\title{
Studies on the Alkaloids of Menispermaceous Plants. CCXLIII. ${ }^{1)}$ Syntheses of Dauricine Type Bases. (3). ${ }^{2)}$ Synthesis of $d l$-Cuspidaline and $d l-4^{\prime}-0$-Methylberbamunine
}

\author{
Masao Tomita, Kazuyoshi Fujitani, Yukio Masaki, \\ and Yasuko Oкамото
}

Faculty of Pharmacentical Sciences, Kyoto University ${ }^{3)}$

(Received March 16, 1967)

\begin{abstract}
A synthesis of $d l$-cuspidaline and $d l-44^{\prime}-\mathrm{O}-$-methylberbamunine was carried out through Bischler-Napieralski reaction followed by separation of the diastereoisomers. The configuration of each racemic diastereoisomer was ascertained by NMR comparisons with the bases of known absolute configuration.
\end{abstract}

Cuspidaline (I) is one of the biscoclaurine alkaloids recently isolated from Limacia cuspidata (MIERS) Hook. f. et THom. collected in Borneo. The structure I for this base was given by spectrometric and degradative studies.4)

The biogenetic role of cuspidaline (I) was discussed ${ }^{4)}$ as it might represent an intermediate to oxyacanthine-berbamine type alkaloids. Assuming intramolecular phenol oxidative coupling of cuspidaline type intermediates, such as cuspidaline (I), berbamunine (II), and magnoline, the biogenesis of oxyacanthine-berbamine series of biscoclaurine alkaloids could resaonably be explained.

This paper describes the sytnhesis of $d l$-form of these biogenetically important intermediates, $d l$-cuspidaline (XII) and its diastereoisomer, $d l-4^{\prime}-0$-methylberbamunine (XIII). The products are to be regarded as key-intermediates in nonenzymatic biogenetic type syntheisis of biscoclaurine alkaloids.

Synthesis of the cuspidaline type bases was performed by a method essentially the same with that described by Kondo, et al.5) in the synthesis of O-methyldauricine methine. 2Methoxy-5,4'-biscarboxymethyldiphenyl ether (III) was condensed with $\beta$-3-methoxy4-benzyloxyphenethylamine (IV), and the resulted bisamide (V) was submitted to BischlerNapieralski cyclization with phosphorus oxychloride in chloroform, to give a bis-3,4-dihydroisoquinoline (VI). VI was reduced with sodium borohydride to bis-1,2,3,4-tetrahydroisoquinoline (VII), which in turn was $\mathrm{N}$-methylated with formalin-sodium borohydride to afford a ditertiary bis-base (VIII). Benzyl protective groups for phenolic hydroxyl of VIII were eliminated by catalytic hydrogenolysis over palladised charcoal, and the cuspidaline type bases (IX) were obtained in an amorphous state.

The product (IX) and natural cuspidaline (I) behaved identically on thin-layer chromatography, ${ }^{6}$ ) and their IR spectra were found to be superimposable. However, NMR spectrometric examination of IX suggested that it consisted of two species of bases diastereo-

1) Part CCXLII: Chem. Pharm. Bull. (Tokyo), 16, 62 (1968).

2) A part of this work was presented at the 16th Annual Meeting of the Kinki Branch, the Pharmaceutical Society of Japan. (Nov. 20, 1966. Fuse.) (Abstracts of Papers, p. 26. cf. Yakugaku Kenkyu, 37, 339 (1966).) Part (2): K. Fujitani and Y. Masaki: Yakugaku Zasshi, 86, 660 (1966).

3) Location : Yoshida-Shimoadachi-cho, Sakyo-ku, Kyoto.

4) M. Tomita, H. Furukawa, and K. Fukagawa, Yakugaku Zasshi, 87,793 (1967); M. Tomita and H. Furukawa, Tetrahedron Letters, 4293 (1966).

5) H. Kondo, Z. Narita, and S. Uyeo, Yakugaku Zasshi, 55, 369 (1935); Ber., 68, 519 (1935).

6) Silica Gel G acc. to Stahl (E. Merck), solvent, MeOH-acetone (1:1); Aluminium Oxide G acc. to Stahl (E. Merck), solvent, $\mathrm{CHCl}_{3}$-acetone $(1: 1)$ or $\mathrm{CHCl}_{3}$. 


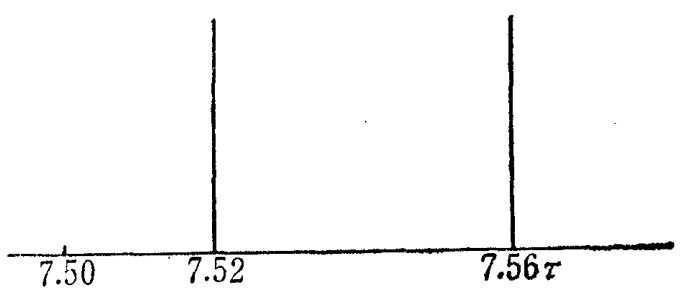

Cuspidaline (I) and $d l$-Cuspidaline (XII)

Mixture of diastereoisomers (IX)
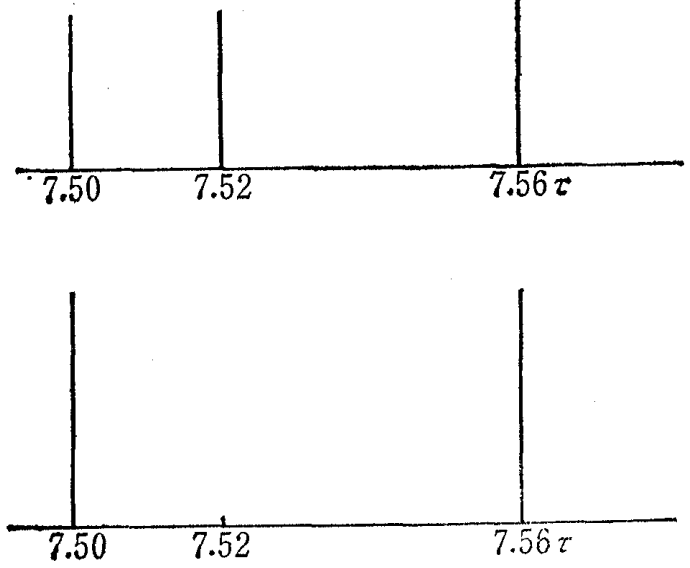

Fig. 1. NMR Spectra of $\mathrm{N}-\mathrm{CH}_{3}$ Signals $d l-4^{\prime}-o-$ Methylberbamunine(XIII)

isomeric each to each. The signal pattern on the whole resembles to that of natural cuspidaline (I), but the signals for the $\mathrm{N}$-methyl groups as shown in Fig. 1 appear in a distinctly different pattern. Confirmation of the character of IX was given by the fact that O,O-dimethyl ether $(\mathrm{X})$ of IX gave an NMR spectrum entirely identical with the reported spectrum?) of the diastereoisomeric mixture $(1: 1)$ of $\mathrm{O}$-methyldauricine and $\mathrm{O}, \mathrm{O}, \mathrm{O}$-trimethylberbamunine.

It was reported $\left.{ }^{7}\right)$ on the spectrometry of dauricine type bases that the diastereoisomers are discriminated from each other by NMR measurements even when their IR spectra in solution are superimposable. The difference of the appearance of their methoxyl signals was noticed, but the assignment of methoxyl signals was left undetermined.

The NMR spectrum of the bistrideuteriomethyl ether (XI), prepared by the treatment of IX with deuteriodiazomethane, was examined to assign the chemical shift value for 7- and $7^{\prime}$-methoxyl groups. The spectrum was found to be superimposable with that of the dimethyl ether (X) except that it lacked signals for two methoxyl groups at 6.38 and $6.42 \tau$.

Therefore, it was proved that 7 - and $7^{\prime}$-methoxyl groups appear at higher field than the other methoxyls, as with the case of "monomeric" $\mathrm{N}$-methylcoclaurine type bases, ${ }^{8)}$ and that the difference in appearance of methoxyl signal patterns of diastereoisomers of dauricine

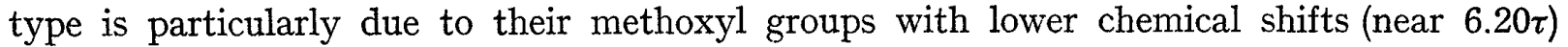
attached at the other positions than $\mathrm{C}-7$ and $\mathrm{C}-7^{\prime}$ positions of the isoquinoline nuclei.

Synthetic cuspidaline base mixture (IX) crystallized after being left standing for several days, and was separated into two species by fractional recystallization from methanol. Almost equal amounts of colorless prisms melting at $143-146^{\circ}$ and colorless needles, mp 179-181 were obtained by the separation.

The base which melts at $143-146^{\circ}$ gave an NMR spectrum superimposable with that of natural cuspidaline (I) except a signal ascribable to methanol at $6.55 \tau$. Elemental analysis

7) K. Fujitani, Y. Aoyagi, and Y. Masaki, Yakugaku Zasshi, 84, 1234 (1964).

8) M. Tomita, T. Shingu, K. Fujitani, and H. Furukawa, Chem. Pharm. Bull. (Tokyo), 13,921 (1965). 
<smiles>COc1cc2c(cc1O)[C@@H](Cc1ccc(CC3c4cc(ccc4OC)Oc4cc(OC)c(O)cc43)cc1)N(C)CC2</smiles>

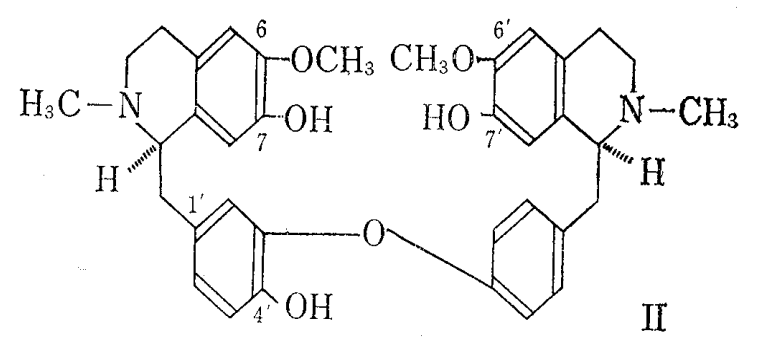

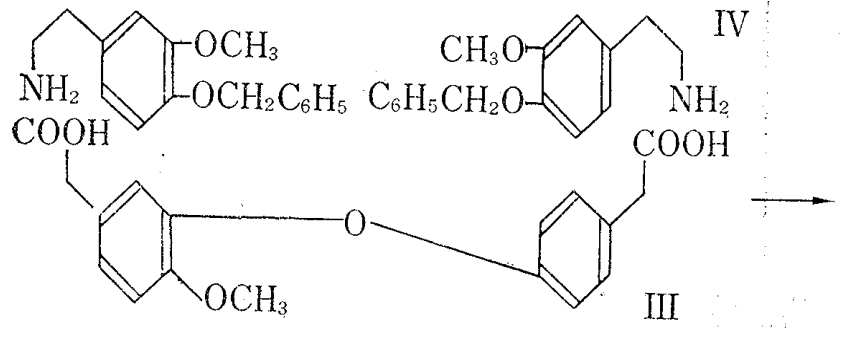

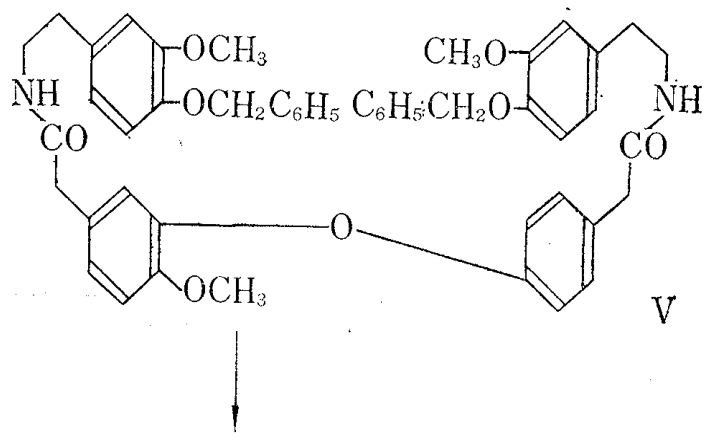

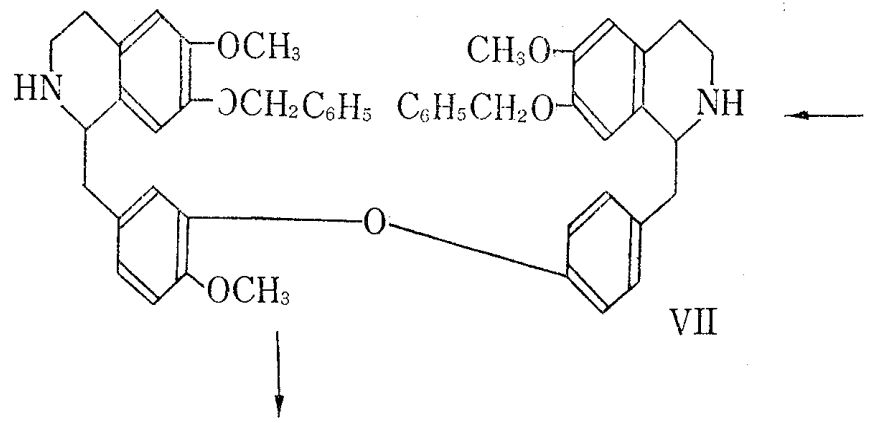

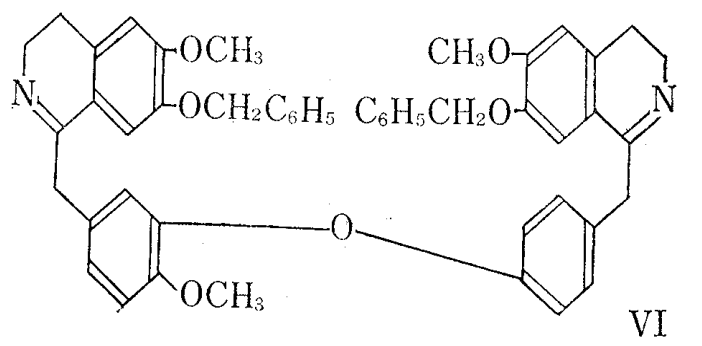

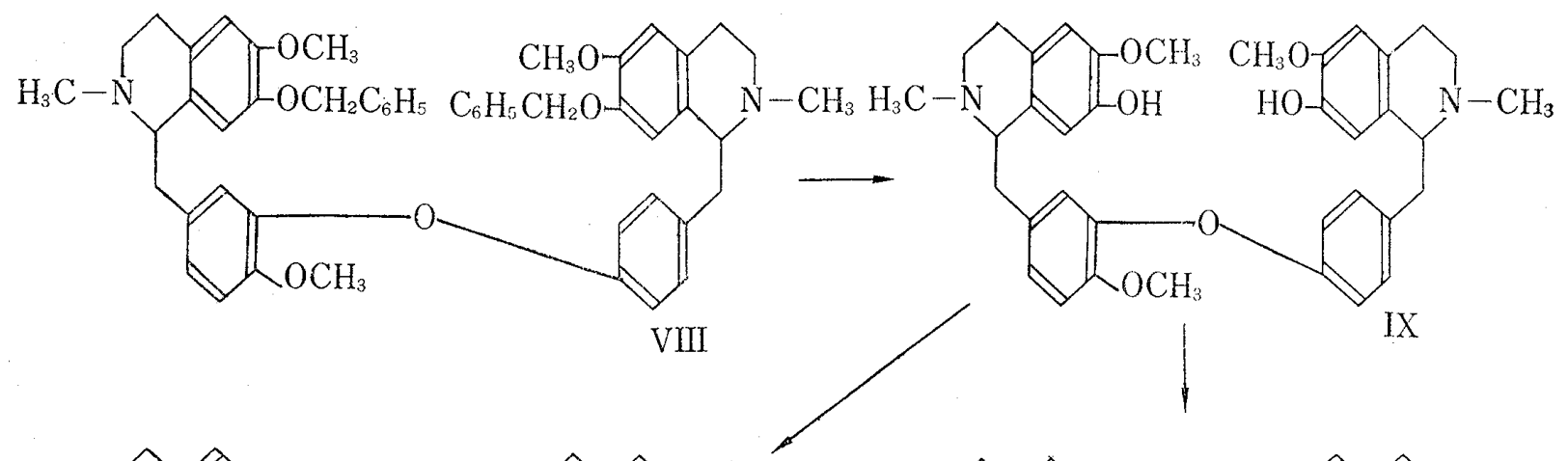

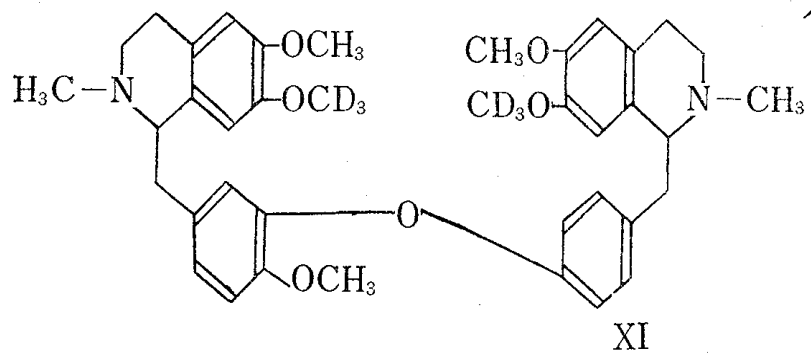

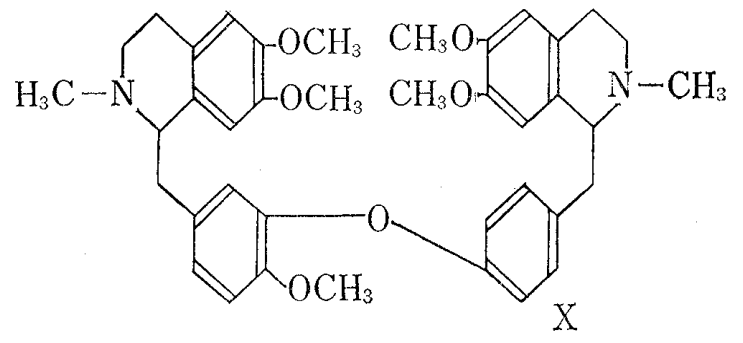

Chart 1

of the base agreed with $\mathrm{C}_{37} \mathrm{H}_{42} \mathrm{O}_{6} \mathrm{~N}_{2} \cdot \mathrm{CH}_{3} \mathrm{OH}$, and it was proved to be $d l$-cuspidaline methanol adduct. Further recrystallization of the base from ethanol gave colorless prisms, mp 167$168^{\circ}$, and the NMR spectrum and elemental analysis of this form completely agreed with dl-cuspidaline formula (XII).

Another base, melting at $179-181^{\circ}$, gave an NMR spectrum very similar to that of $d l$ cuspidaline (XII) in relative intensities of signals, though slight but recognizable differences 
in the signal patterns were noticed. Especially the appearance of N-methyl signals was clearly different from that of $a l$-cuspidaline (XII) as shown in Fig. 1. Elemental analysis agreed with $\mathrm{C}_{37} \mathrm{H}_{42} \mathrm{O}_{6} \mathrm{~N}_{2}$. Thus, it was assumed that the base with higher melting point was the diastereoisomer (XIII) of $d l$-cuspidaline (XII). This was confirmed by the NMR comparison of the base methyl ether (XIV) with $\mathrm{O}, \mathrm{O}, \mathrm{O}$-trimethylberbamunine $\left(\mathrm{XIV}^{\prime}\right)$, derived from natural berbamine (XV), as they gave completely superimposable spectra.

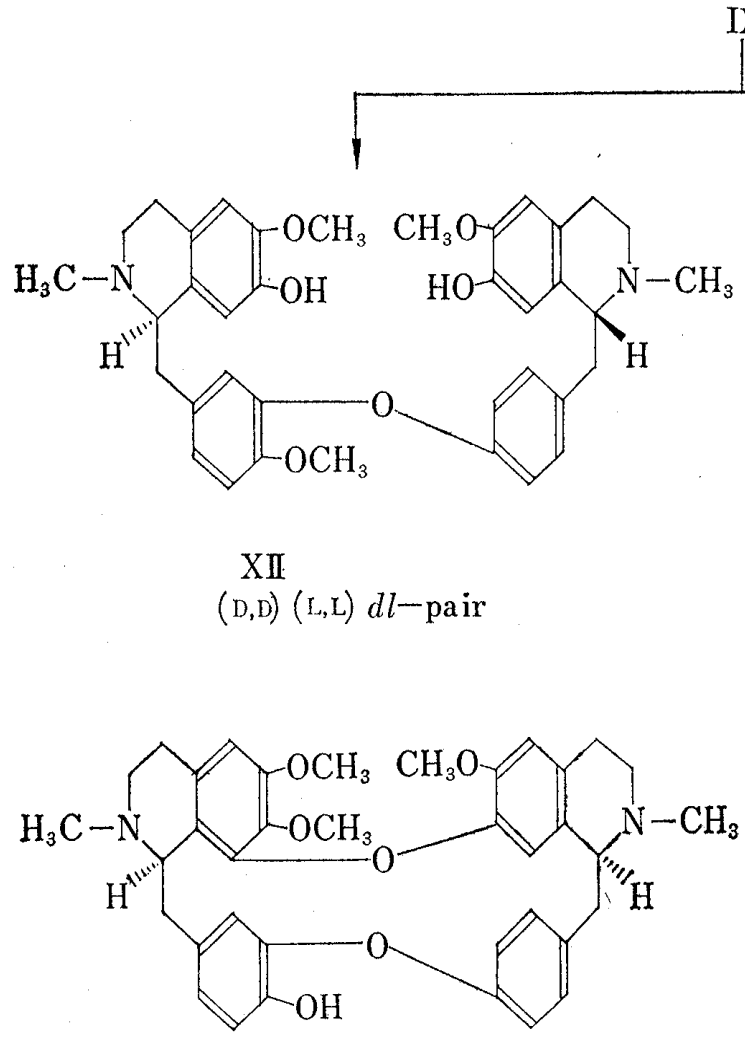

$\mathrm{XV}$<smiles>COc1ccc(CCN(C)[C@@H]2Cc3ccc(cc3)Oc3ccc2cc3OC)cc1OC</smiles>

XIV $\quad(D, L)(L, D) d l-$ pair

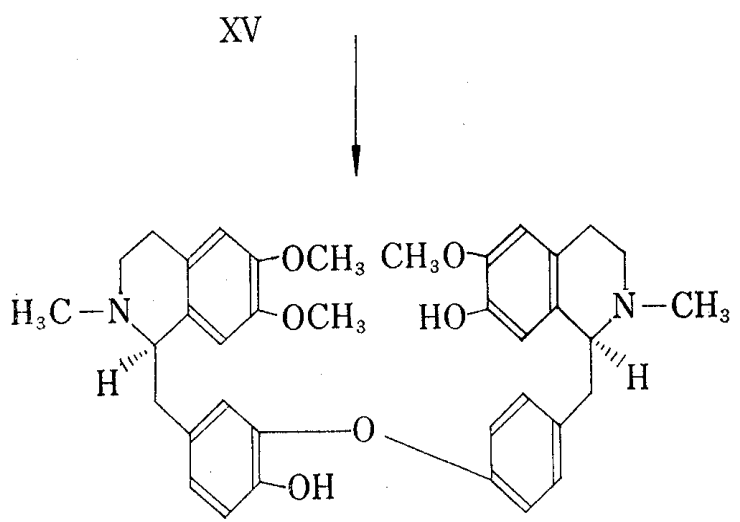<smiles>COc1cc(C[C@H]2c3cc(O)c(OC)cc3CCN2C)ccc1O</smiles>

XIII $\mid$ (D,L) (L,D) $d l-$ pair

XVI

Chart 2

A $d l$-pair was represented by the formula of the one enantiomer.

Therefore, the separation of diastereiosomers of dauricine type base was accomplished for the first time, and the configuration of the each product was clarified.

Further, examination of the separating diastereoisomers at the stage of bis-N-nor base (VII) was carried out. Bis-1,2,3,4,--tetrahydroisoquinoline (VII) oxalate was recrystallized from methanol, and the recrystallize material was treated in usual manner to afford IX. The obtained final product (IX) showed in NMR spectrometry that it consisted of larger amount of $d l$-cuspidaline (XII) and smaller amount of the diastereoisomer (XIII). The 
mother liquor of the recrystallization was also submitted to N-methylation and debenzylation, and the product was found on NMR spectrometry to consist of smaller amount of $d l$-cuspidaline (XII) and larger amount of $d l-4^{\prime}-\mathrm{O}$-methylberbamunine (XIII).

These findings on NMR spectrometry suggested that the separation of diastereoisomers might also be applicable at the bis-N-nor stage (VII) of the synthetic reaction sequence.

\section{Experimental $\left.{ }^{9}\right)$}

$N, N^{\prime}$-Bis $\left(\beta\right.$-3-methoxy-4-benzyloxyphenethyl)-2-methoxydiphenyl Ether $5,4^{\prime}$-Diacetamide $(\mathrm{V})$ - To a mixture of $\beta$-3-methoxy-4-benzyloxyphenethylamine (IV) (7.5 g) and 2-methoxy-5,4'-biscarboxymethyldiphenyl ether (III) $(5 \mathrm{~g}$ ) was added $50 \mathrm{ml}$. of decalin and heated under reflux for $1 \mathrm{hr}$. After cooling, the decalin was decanted off, and the residue was washed with ether and dissolved in $\mathrm{CHCl}_{3}$. The $\mathrm{CHCl}_{3}$ solution was shaken successively with $5 \% \mathrm{HCl}$ and $2 \% \mathrm{NaOH}$, then dried over anhyd. $\mathrm{K}_{2} \mathrm{CO}_{3}$. Evaporation of the solvent gave $12 \mathrm{~g}$ of crude crystalline product, which was recrystallized from methanol to give $8 \mathrm{~g}$ of colorless microcrystalline, $\mathrm{mp} 96^{\circ}\left(\right.$ lit. $\left.^{10)} \mathrm{mp} 109-110^{\circ}\right) . \quad \mathrm{C}_{49} \mathrm{H}_{50} \mathrm{O}_{8} \mathrm{~N}_{2}$. Anal. Calcd.: C, 74.03; H, 6.34 . Found: C, 74.21; H, 6.58. IR $\left(\mathrm{CHCl}_{3}\right) \mathrm{cm}^{-1}: \nu_{\mathrm{C}=0} 1660$.

2-Methoxy-5,4'-bis(6-methoxy-7-benzyloxy-1,2,3,4-tetrahydroisoquinolin-1-ylmethyl)diphenyl Ether (VII) -A mixture of $5 \mathrm{~g}$ of the bisamide $(\mathrm{V}), 10 \mathrm{~g}$ of $\mathrm{POCl}_{3}$, and $75 \mathrm{ml}$ of $\mathrm{CHCl}_{3}$ was refluxed for $2 \mathrm{hr}$. The solvent and excess $\mathrm{POCl}_{3}$ were evaporated off in vacuo, and the residue was treated with samll amount of dil. $\mathrm{HCl}$, then washed with ether, and extracted with $\mathrm{CHCl}_{3}$. The $\mathrm{CHCl}_{3}$ solution was dried over anhyd. $\mathrm{Na}_{2} \mathrm{SO}_{4}$, and the solvent was evaporated to give crude 2-methoxy-5,4'-bis(6-methoxy-7-benzyloxy-3,4dihydroisoquinolin-1-ylmethyl)diphenyl ether (VI) dihydrochloride as an oily substance (yield: $5 \mathrm{~g}$ ). The obtained 3,4-dihydroisoquinoline (VI) dihydrochloride was dissolved in a mixture of $150 \mathrm{ml}$ of $\mathrm{MeOH}$ and $20 \mathrm{ml}$ of $\mathrm{CHCl}_{3}$, and to this solution $2.5 \mathrm{~g}$ of $\mathrm{NaBH}_{4}$ was added in portions with stirring at room temperature; the stirring was continued for $30 \mathrm{~min}$ after all the $\mathrm{NaBH}_{4}$ was added, then the solvent mixture was evaporated to dryness. The residue was treated with dil. $\mathrm{NaOH}$ and extracted with $\mathrm{CHCl}_{3}$. The $\mathrm{CHCl}_{3}$ solution was dried over anhyd. $\mathrm{K}_{2} \mathrm{CO}_{3}$, then the solvent was evaporated to give crude 1,2,3,4-tetrahydroisoquinoline (VII) as an oily residue (yield: $4 \mathrm{~g}$ ). Oxalate: recrystallized from $\mathrm{EtOH}, \mathrm{mp} 155^{\circ} . \mathrm{C}_{49} \mathrm{H}_{50^{-}}$ $\mathrm{O}_{6} \mathrm{~N}_{2} \cdot 2 \mathrm{C}_{2} \mathrm{H}_{2} \mathrm{O}_{4} \cdot 1^{1} / 2 \mathrm{H}_{2} \mathrm{O}$. Anal. Calcd.: C, $65.63 ; \mathrm{H}, 5.82$. Found: C, 65.81; H, 5.94 .

2-Methoxy-5, 4'-bis(2-methyl-6-methoxy-7-benzyloxy-1,2,3,4-tetrahydroisoquinolin-1-ylmethyl) diphenyl Ether (VIII) - To a solution of $3.7 \mathrm{~g}$ of (VII) in a mixture of $80 \mathrm{ml}$ of $\mathrm{MeOH}$ and $25 \mathrm{ml}$ of $\mathrm{CHCl}_{3}, 1.2 \mathrm{~g}$ of $37 \%$ formalin was added dropwise with stirring at room temperature, and the stirring was continued for $30 \mathrm{~min}$, then $1 \mathrm{~g}$ of $\mathrm{NaBH}_{4}$ was added in small portions to the solution with stirring. After additional stirring for $30 \mathrm{~min}$, the solvents were evaporated in vacuo, and the residue was treated with dil. $\mathrm{NaOH}$, then extracted with ether. Ethereal solution was dried over anhyd. $\mathrm{K}_{2} \mathrm{CO}_{3}$ and the solvent was evaporated to give $3.5 \mathrm{~g}$ of $\mathrm{N}$-methylated base (VIII) as an oily substance.

2-Methoxy-5, 4'-bis(2-methyl-6-methoxy-7-hydroxy-1,2,3,4-tetrahydroisoquinolin-1-ylmethyl)diphenyl Ether (IX) (Diastereoisomeric Mixture of $d l$-Cuspidaline (XII) and $d l$-4'-0-Methylberbamunine (XIII) — - Four grams of VIII was dissolved in $200 \mathrm{ml}$ of $\mathrm{EtOH}$, and $16 \mathrm{ml}$ of $1 \% \mathrm{PdCl}_{2}$ and $1.6 \mathrm{~g}$ of active charcoal (Darco G 60) were added, then stirred under the stream of hydrogen under atmospheric pressure at room temperature. After the consumption of hydrogen ceased, the catalyst was filtered off, and the filtrate was condensed to dryness, then dissolved in dil. $\mathrm{HCl}$. Acidic solution was washed with ether to remove the unchanged material, then made ammoniacal alkaline with the addition of $\mathrm{NH}_{4} \mathrm{Cl}$, and extracted with $\mathrm{CHCl}_{3}$. The extract was dried over anhyd. $\mathrm{K}_{2} \mathrm{CO}_{3}$, and the solvent was distilled off to give $2.86 \mathrm{~g}$ of amorphous powder. The residue behaved identically in color and spots on thin-layer chromatography with natural cuspidaline (I). The IR $\left(\mathrm{CHCl}_{3}\right)$ spectrum was superimposable with that of natural cuspidaline (I).

Fractional Recrystallization of IX into $d l$-Cuspidaline (XII) and $d l-4^{\prime}-0$-Methylberbamunine (XIII) The base mixture (IX) $(700 \mathrm{mg})$ was repeatedly recrystallized from $\mathrm{MeOH}$. Prismatic crystals were obtained first from the crystalline fractions of the recrystallization, then needles came from the mother liquor portions, and finally $100 \mathrm{mg}$ of colorless prisms, $\mathrm{mp} 143-146^{\circ}$, and $100 \mathrm{mg}$ of colorless needles, $\mathrm{mp}$ $179-181^{\circ}$ were obtained.

The NMR spectrum of prisms with lower melting point was identical with that of natural cuspidaline (I) except a signal at $6.55 \tau$ (singlet, $3 \mathrm{H}$ ) due to the methyl group of the solvent. $\mathrm{C}_{37} \mathrm{H}_{42} \mathrm{O}_{6} \mathrm{~N}_{2} \cdot \mathrm{CH}_{3} \mathrm{OH}$. Anal. Calcd.: C, 71.00; H, 7.21. Found: C, 70.70; H, 7.39. The prisms from $\mathrm{MeOH}$ were further recrys-

9) Melting points were determined on a Yanagimoto Micro Melting Point Apparatus and uncorrected. NMR spectra were taken on a Varian A-60 spectrometer at $60 \mathrm{Mc}$ in $\mathrm{CDCl}_{3}$ with $\mathrm{Me}_{4} \mathrm{Si}$ as an internal standard.

10) I.N. Gorbacheva, L.P. Varnakova, E.M. Kleiner, I.I. Chernova, and N.A. Preobrazhenskii, Zh. Obshch. Kh., 28, 167 (1958). 
tallized from EtOH to give colorless prisms melting at $167-168^{\circ}$. The NMR spectrum of the prisms from EtOH was identical with natural cuspidaline (I) in every respect. $\mathrm{C}_{37} \mathrm{H}_{42} \mathrm{O}_{6} \mathrm{~N}_{2}$. Anal. Calcd.: C, 72.76; $\mathrm{H}, 6.93$. Found: $\mathrm{C}, 72.55 ; \mathrm{H}, 7.22$.

The needles from $\mathrm{MeOH}$ with $\mathrm{mp} 179-181^{\circ}$, gave superimposable IR $\left(\mathrm{CHCl}_{3}\right)$ spectrum with that of natural cuspidaline (I), and behaved identically on TLC. Thd NMR spectrum has its N-methyl signals at $\tau: 7.56,7.50$ (singlets, $2 \times 3 \mathrm{H}$ ); and methoxyl signals at $\tau: 6.18$ (overlapped singlets, $3 \times 3 \mathrm{H}$ ) (natural cuspidaline: $\left.7.56,7.52 \tau\left(6 \mathrm{H}, 2 \times \mathrm{NCH}_{3}\right), 6.18 \tau\left(9 \mathrm{H}, 3 \times \mathrm{OCH}_{3}\right)\right) . \quad \mathrm{C}_{37} \mathrm{H}_{42} \mathrm{O}_{6} \mathrm{~N}_{2} . \quad$ Anal. Calcd.: C, 72.76; $\mathrm{H}, 6.93$. Found: $\mathrm{C}, 72.75 ; \mathrm{H}, 7.16$.

2-Methoxy-5,4'-bis(2-methyl-6,7-dimethoxy-1,2,3,4-tetrahydroisoquinolin-1-ylmethyl)diphenyl Ether (X) -The amorphous mixture (IX) $(260 \mathrm{mg}$ ) was dissolved in a mixture of $4 \mathrm{ml}$ of $\mathrm{MeOH}$ and $10 \mathrm{ml}$ of ether, and the excess $\mathrm{CH}_{2} \mathrm{~N}_{2}-\mathrm{Et}_{2} \mathrm{O}$ was added. After standing overnight, the reaction mixture was treated by usual procedure, and an oily non-phenolic base $(\mathrm{X})(250 \mathrm{mg})$ was obtained. The NMR spectrum was identical with that?) of equimolecular mixture of $\mathrm{O}$-methyldauricine $(\mathrm{D}, \mathrm{D})$ and $\mathrm{O}, \mathrm{O}, \mathrm{O}-$ trimethylberbamunine $(\mathrm{D}, \mathrm{L})$.

2-Methoxy-5,4'-bis(2-methyl-6-methoxy-7-trideuteriomethoxy-1,2,3,4-tetrahydroisoquinolin-1-ylmethyl)diphenyl Ether (XI) - One hundred milligrams of the amorphous base mixture (IX) was dissolved in a mixture of $4 \mathrm{ml}$ of dioxane and $0.5 \mathrm{ml}$ of deuterium oxide, and to this solution $\mathrm{CD}_{2} \mathrm{~N}_{2}$-dioxane ${ }^{11}$ ) was added with stirring at room temperature. After standing overnight, dil. $\mathrm{HCl}$ was added to destroy excess $\mathrm{CD}_{2} \mathrm{~N}_{2}$, and the solvent was removed. The residue was treated in usual manner, to give an oily non-phenolic base (XI) $(70 \mathrm{mg})$ NMR spectrum was superimposable with that of the O-methyl ether (X) except that it lacked the signals at $6.38,6.42 \tau\left(2 \times \mathrm{OCH}_{3}\right)$ of $\mathrm{X}$.

$d l-0,0,0-T r i m e t h y l b e r b a m u n i n e(X I V)$ _ Fifteen milligrams of $d l-4^{\prime}-\mathrm{O}$-methylberbamunine (XIII) $\left(\mathrm{mp} 179-181^{\circ}\right.$ ) was dissolved in a mixture of $2 \mathrm{ml}$ of $\mathrm{MeOH}, 0.5 \mathrm{ml}$ of $\mathrm{CHCl}_{3}$, and $20 \mathrm{ml}$ of ether, and then excess $\mathrm{CH}_{2} \mathrm{~N}_{2}-\mathrm{E} t_{2} \mathrm{O}$ was added to the solution. Treatment in usual manner after standing overnight, gave $13 \mathrm{mg}$ of non-phenolic product (XIV). The NMR spectrum was superimposable with that of $\mathrm{O}, \mathrm{O}, \mathrm{O}-$ trimethylberbamunine $(\mathrm{D}, \mathrm{L})\left(\mathrm{XIV}^{\prime}\right)$ derived from natural berbamine $(\mathrm{XV})$.

Preparation of $0,0,0$-Trimethylberbamunine $\left(\mathrm{XIV}^{\prime}\right)$ from Berbamine $(\mathrm{XV})-\mathrm{A}$ modification of the described method ${ }^{12}$ ) was employed, and the diphenolic intermediate (XVI) was isolated and characterized.

To a mixture of $c a .300 \mathrm{ml}$ of liquid ammonia and $100 \mathrm{ml}$ of anhyd. ether, metallic sodium and a solution of $1.0 \mathrm{~g}$ of berbamine (XV) benzene adduct (in $30 \mathrm{ml}$ of anhyd. toluene diluted to $100 \mathrm{ml}$ with anhyd, ether) were added alternately each in small portions; the reaction temperature was being kept -50 to $-55^{\circ}$ by means of Dry Ice-acetone bath. After consuming $0.7 \mathrm{~g}$ of metallic sodium, the reaction was ceased by adding $\mathrm{NH}_{4} \mathrm{Cl}$, and the product was worked up in a usual manner, to give a phenolic base (XVI) $(0.98 \mathrm{~g})$. The product (XVI) crystallized on trituration with $\mathrm{CH}_{2} \mathrm{Cl}_{2}$-hexane, and was recrystallized from the same solvent mixture. Colorless needles, mp $161-164^{\circ} . \quad[\alpha]_{\mathrm{D}}^{27}+61.1^{\circ}\left(c=1.44 \mathrm{CHCl}_{3}\right) . \quad$ Anal. Calcd.: $\mathrm{C}_{37} \mathrm{H}_{42} \mathrm{O}_{6} \mathrm{~N}_{2}$. Anal. Calcd.: C, $72.76 ; \mathrm{H}, 6.93 ; \mathrm{N}, 4.59$. Found: $\mathrm{C}, 73.01 ; \mathrm{H}, 7.16 ; \mathrm{N}, 4.35$.

XVI $(100 \mathrm{mg})$ was dissolved in small volume of $\mathrm{CH}_{2} \mathrm{Cl}_{2}$, and excess $\mathrm{CH}_{2} \mathrm{~N}_{2}-\mathrm{Et} \mathrm{t}_{2} \mathrm{O}$ was added. After standing for 4 days, the solvent was removed. The residue was taken into dil. $\mathrm{HCl}$, then the solution was basified with $\mathrm{NaOH}$ and extracted with ether. Ethereal solution was washed with dil. $\mathrm{NaOH}$ and water, dried over anhyd. $\mathrm{K}_{2} \mathrm{CO}_{3}$. Removal of the solvent gave $99 \mathrm{mg}$ of light brown oil, which was purified by column chromatography $\left(\mathrm{Al}_{2} \mathrm{O}_{3}\right.$-benzene) to give $88 \mathrm{mg}$ of colorless oil (XVI). IR $\left(\mathrm{CHCl}_{3}\right)$ : identical with the spectrum of $\mathrm{O}-$-methyldauricine. $\left.{ }^{13}\right) \quad[\alpha]_{\mathrm{D}}^{17}+31.84^{\circ}\left(c=0.314, \mathrm{Me}_{2} \mathrm{CO}\right)\left(\right.$ lit. $\left.^{14}\right)[\alpha]_{\mathrm{D}}^{10}+52.6^{\circ}, c=0.3042$, $\left.\mathrm{Me}_{2} \mathrm{CO}\right)[\alpha]_{\mathrm{D}}^{17}+21.69^{\circ}\left(c=2.58, \mathrm{CHCl}_{3}\right)$

XVI dimethiodide: pale yellow needles, $\mathrm{mp} 183-185^{\circ}$. Mixed $\mathrm{mp}$ with authentic O,O,O-trimethylberbamunine dimethiodide ${ }^{14}$ ) did not depress. IR (Nujol) was identical with that of authentic specimen.

Acknowledgement The authors wish to thank Dr. T. Shingu of this Faculty for NMR measurements. They are also indebted to the members of the Microanalytical Center of this University for elemental analyses.

11) K.J. van der Merwe, P.S. Steyn, and S.H. Eggers, Tetrahedron Letters, 3925 (1965).

12) Y. Inubushi, Yakugaku Zasshi, 72, 220 (1952).

13) M. Tomita and Y. Okamoto, Yakugaku Zasshi, 84, 1030 (1964).

14) M. Tomita and T. Kugo, Yakugaku Zasshi, 77, 1079 (1957). 